This document is the accepted manuscript version of the following article:

Hering, J. G., Nunnenmacher, L., \& Von Waldow, H. (2018). Perspectives from a water research institute on knowledge management for sustainable water management. In M. Russ (Ed.), Handbook of knowledge management for sustainable water systems (pp. 15-33). Hoboken: Wiley. http:// doi.org/10.1002/9781119271659.ch1

\title{
Perspectives from a water research institute on knowledge management for sustainable water management
}

Janet G. Hering, ${ }^{*, 1,2,3}$ Lothar Nunnenmacher ${ }^{1}$ and Harald von Waldow ${ }^{1}$

${ }^{1}$ Eawag, Swiss Federal Institute for Aquatic Science and Technology, CH-8600 Dübendorf, Switzerland

${ }^{2}$ Swiss Federal Institute of Technology (ETH) Zürich, IBP, CH-8092 Zürich, Switzerland

${ }^{3}$ Swiss Federal Institute of Technology Lausanne (EPFL), ENAC, CH-1015 Lausanne, Switzerland

* (corresponding author) E-mail: janet.hering@eawag.ch

submitted as a "case study" chapter for inclusion in the Handbook of Knowledge Management for Sustainable Water Systems (KM4SWS), ed. M. Russ, Wiley series Challenges in Water Management

initial submission 30 January 2017, revised version submitted 10 May 2017

\begin{abstract}
A sizeable, and sometimes overwhelming, array of knowledge is available and relevant to Sustainable Water Management (SWM). This knowledge derives not only from the natural, social and engineering sciences but also from practical experiences in water management, which is defined broadly to include all forms of water use as well as the protection of water resources and reduction of risk from water-related hazards. As a publically-funded water research institute, Eawag (the Swiss Federal Institute of Aquatic Science and Technology) faces the challenges of integrating and synthesizing available knowledge, creating new knowledge through research projects and making knowledge available in an accessible form to support engineering practice, water resources management and related policy-making. This chapter examines these challenges from an organizational perspective, discussing measures taken within Eawag to meet them and identifying remaining gaps and possible ways to address them.
\end{abstract}

\section{Keywords}

data repository, open access, peer review, Sustainable Development Goals, text mining 


\section{Introduction}

Sustainable Water Management (SWM) is a domain in which the aspects of knowledge as a public good [van Kerkhoff, 2013] are intuitively obvious. This derives from the fact that water management has been a core responsibility of civil society throughout history [Mays, 2010; Sedlak, 2014]. Here, water management is defined broadly to encompass:

- Water supply and use (e.g., for drinking water, irrigation, aesthetics, fire protection, etc.)

- Water resources protection (e.g., for fisheries, recreation and provision of other ecosystem services)

- Management of watercourses and infrastructure (e.g., for navigation, flood protection, water and wastewater conveyance)

With this broad definition, water management must necessarily address competing uses and interests, taking into account natural, technical and societal factors [Hering and Vairavamoorthy, 2017]. Whether water management can be characterized as sustainable (in a given context) will depend on whether deficits in one type of factor, such as limited natural water availability, can be offset by other factors (e.g., demand management and/or infrastructure for water storage). Conversely, sustainability is unlikely to be realized when deficits are aggravated by, for example, limited human capacity and economic resources. Meaningful approaches to SWM can only be identified and implemented in local and regional contexts [Hering et al., 2015].

A huge, even overwhelming, array of knowledge is available that is highly relevant to SWM. This knowledge, which derives not only from the natural, social and engineering sciences but also from practical experiences in water management, reflects a massive investment of resources on the part of civil society. Having access to SWM-relevant knowledge could allow society to conserve its resources by using (rather than re-inventing) existing knowledge. It might also be possible to avoid unintended, adverse consequences by understanding past failures and, as well, the factors that contributed to past successes and might limit their replication under different conditions. In addition, tapping SWM-relevant knowledge could contribute to understanding what conditions would be amenable to "leapfrogging" as compared with those that are likely to require the progressive development of systems or approaches for water management [Briscoe, 2011]. Ultimately, the goal of improving access to SWM-relevant knowledge would be to provide the most useful knowledge base for decision-making [Cash et al., 2003; Cornell et al., 2013; Hering, 2015; Martinuzzi and Sedlacko, 2016; van Kerkhoff, 2013; van Kerkhoff and Lebel, 2006; van Kerkhoff and Szlezak, 2016]. This need is especially pressing in light of the commitment of the nations of the world to achieve the Sustainable Development Goals by 2030 [UN, 2015]. Water supply, sanitation and the quality of receiving waters are addressed explicitly in Goal 6 "Ensure access to water and sanitation 
for all" and also in the Goal 11 targets to reduce the impact of water-related disasters and the adverse per capita impacts of cities.

In this chapter, issues of knowledge management (KM) as applied to SWM are examined from the perspective of a single organization, the Swiss Federal Institute of Aquatic Science and Technology (Eawag). Constraining the scope of this analysis to Eawag is intended to allow specific needs and demands with regard to KM to be clearly identified and characterized, not only for issues arising within Eawag but also issues that arise for Eawag as a member of the SWM community. This approach is intended to provide a basis for assessing measures to meet $\mathrm{KM}$ needs as well as barriers to KM that would need to be circumvented and, ideally, for proposing new approaches that could be pursued within Eawag or in cooperation with external partners.

\section{The setting - Eawag's funding, scope and mandate}

Eawag is a publically-funded research institute that receives approximately $75 \%$ of its funding through direct support from the Swiss federal government. With this level of direct support, it is particularly incumbent upon Eawag to use its resources efficiently; effective KM is an integral aspect of efficient resource utilization.

The scope of Eawag's activities is legally defined ${ }^{1}$ and encompasses the following topics:

- Chemistry, physics, biology and microbiology of water

- Ecology of aquatic systems

- Drinking water and wastewater treatment technologies

- Sustainable management of water supply and resources and of the water environment

Eawag's thematic scope focuses mainly on water quality, which reflects both the history of the organization [Eawag, 2011] and the abundance of water resources in Switzerland. Issues related to flooding are mainly addressed by the Swiss Federal Institute for Forest, Snow and Landscape Research (WSL) though Eawag collaborates with WSL on projects dealing with aspects of flooding and flood protection that pertain to water quality and aquatic ecology.

Eawag is one of six institutions belonging to the Domain of the Swiss Federal Institutes of Technology (ETH Domain). These six institutions share a common mandate in research, education and expert consulting. Since Eawag does not grant degrees, it fulfills its mandate in tertiary education in cooperation with the Swiss Federal Institutes of Technology in Zurich (ETH Zurich) and Lausanne (EPFL), the Swiss Cantonal Universities and Universities of Applied Sciences, and also with international, degree-granting partners.

Eawag's expert consulting in context of industrialized countries is mainly focused on Switzerland with further engagement in Europe resulting from common interests and projects. Many of Eawag's

\footnotetext{
${ }^{1}$ https://www.admin.ch/opc/de/classified-compilation/20032108/index.html (in German)
} 
applied projects in Switzerland are funded by the federal, cantonal and local authorities and are often conducted jointly with water and wastewater utilities. Eawag conducts expert consulting and research in low- and middle-income countries (LMICS) with support from the Swiss Agency for Development and Cooperation (SDC), the State Secretariat for Economic Affairs (SECO) and charitable foundations.

Because of its engagement with ETH Zurich, EPFL and the Swiss Cantonal Universities (which include joint professorial appointments), Eawag's research benefits greatly from the participation of doctoral students as well as Masters and Bachelors students conducting projects and thesis research. The short residencies of students (especially as compared with Eawag's permanent scientific staff) poses specific challenges for KM. Summary statistics (for 2016) are presented in Table 1.

\section{[approximate location for Table 1]}

\section{Understanding SWM-related demands for KM at Eawag}

Eawag, as an organization with a focus on applied research, must manage a broad range of knowledge and information. Here the focus is on demands for KM that relate directly to SWM; knowledge management relating to organizational operation and performance is excluded. ${ }^{2}$ In addition, SWM as an area of research shares many KM needs with other applied (and even fundamental) research areas. Some KM tools, structures and/or frameworks are generally applicable (i.e., to topics beyond SWM).

An important aspect of SWM is that relevant knowledge includes not only technical knowledge (which derives mainly from the natural, social and engineering sciences) but also experiential and practical knowledge, which is often tacit [Tsoukas, 2011]. SWM knowledge that derives from practical experience often develops during the interaction with stakeholders or practitioners in the context of applied projects or expert consulting. The tendency for such knowledge to remain as tacit, informal knowledge (which is held by individuals or, in the best cases, within networks) limits its wider application in SWM. An important challenge (but also opportunity) for Eawag is how to articulate and access experiential and practical knowledge gained by its researchers through interactions with practice.

Demands for SWM-related knowledge can also have different drivers. Internally-driven demands include the need for Eawag researchers to position proposed SWM projects and/or interpret the results of SWM projects in the context of previous relevant work. Analysis of gaps in existing SWM-related knowledge is generally needed as a justification for further research. Externally-driven demands arise from needs in engineering practice, water resources management and/or policy-making that may be linked with concrete projects or with formal or informal

\footnotetext{
${ }^{2}$ Eawag reports operational statistics to the Board of the ETH Domain, which publishes summary statistics for all ETH Domain institutions in its Annual Reports (https://www.ethrat.ch/en/annualreport 2016).
} 
consultation. Externally-driven demands are often highly contextual, posing the challenge of how to incorporate context adequately while still being able to identify and extract generalizable aspects.

\section{Current measures to meet SWM-related demands for KM at Eawag}

Eawag's capacities for knowledge management have expanded over time, in concert with changing demands and opportunities. As related technologies (mainly in IT) develop, it is a constant challenge to decide on and make appropriate investments (including the decision to develop new capacities in house vs. out-sourcing). Perhaps even more challenging, though, is fostering new attitudes and norms regarding, for example, data management and data sharing to comply in a meaningful way with changing external expectations.

\section{Data management}

The rapidly-developing trend toward more systematic data management is a response to evolving norms in the scientific community [Fecher et al., 2015; Soranno et al., 2015], which in turn reflect both the expectations of the broader society for return on its investment in scientific research and the availability of tools for data management [Joseph, 2016]. The fact that much scientific research is publically funded underlies growing requirements for measures ranging from the specification of data availability to public data archiving [Kowalczyk and Shankar, 2011; Vines et al., 2013].

Data Management Plans (DMPs) are increasingly required by funding agencies and DMP tools ${ }^{3}$ are being developed to support them. An accord for "Open Data in a Big Data World" has been endorsed by national scientific academies, scientific organizations, universities and research institutes (http://www.science-international.org/). Some publishers have adopted the Joint Data Archiving Policy (http://datadryad.org/pages/jdap) or comparable policies that require the publication-supporting data to be publicly available [Michener, 2015]. This is also of direct interest to researchers because of the citation benefits associated with open data [Piwowar and Vision, 2013]. However, the availability of reliable public repositories for data deposition varies widely among the scientific disciplines in which Eawag is engaged and the quality of deposited data is subject to criticism [Roche et al., 2015]. The Registry of Research Data Repositories, re3data.org [Pampel et al., 2013], listed 1805 research data repositories when this chapter was written. Zenodo (https://zenodo.org) and Dryad (https://datadryad.org) are among the most used general-purpose repositories at Eawag. Options are increasing to publish data sets as products in journals such as Earth System Science Data or Scientific Data and to assign digital object identifiers (DOIs) to data sets

\footnotetext{
${ }^{3}$ Data Management Plan (DMP) Tool, Univ. of California (https://dmp.cdlib.org/); DMP Online, Digital Curation Centre (https://dmponline.dcc.ac.uk/)
} 
(e.g., https://www.datacite.org/) or to publish single observations after peer review (https://www.sciencematters.io/) or "nanopublications" [Groth et al., 2010].

Since 1972, Eawag has collaborated with the Swiss Federal Office of the Environment (FOEN) and the WSL in the National Long-term Surveillance of Swiss Rivers (NADUF) program. Through this program, standardized monitoring data on water quality are made available through the Eawag website (http://www.eawag.ch/en/department/wut/main-focus/chemistry-of-waterresources/naduf/) to accompany hydrologic data available through the FOEN website. Note that other water data portals (i.e., websites with data or links to monitoring data on water resources including flow, water quality and integrated water resources management) [Hering, 2017] are an important resource for Eawag researchers.

Currently, a central research data (CRD) repository is being established at Eawag to provide intermediate- and long-term storage for datasets (Figure 1). This project is intended to support compliance with standards of good scientific practice for data retention and to enable the long-term archiving of unique, unrepeatable measurements. An additional anticipated benefit is increased collaboration within Eawag, including re-use of data that are discoverable through appropriate search queries. Data sets can be filtered by location, sampling periods, keywords and terms from several controlled vocabularies.

\section{[approximate location for Figure 1]}

It is hoped that these ancillary benefits will help to motivate individual researchers to perform the organization, quality control and annotation of their data that is needed for a reliable research data repository. Additional activities related to the establishment of the repository include the provision of guidelines, training and ancillary tools and services to support researchers with their data-management and data-handling needs and thus to make usage as efficient and painless as possible.

Eawag's multidisciplinary environment (in which highly heterogeneous types of data are generated) necessitates substantial customization of its repository system. The open-source software CKAN (http://ckan.org/) was chosen largely because it is sufficiently modifiable to meet the broad spectrum of user requirements [Amorim et al., 2015]. Additionally, different groups require different ancillary tools to support the submission of data sets. For example, reliable uploading of large genomic datasets (10s to 100s of GB) requires a fully-featured command-line client script running on Linux (https://github.com/eawag-rdm/resup\#resup), while conversion of proprietary fileformats to standardized ones is best served by MS Windows-based tools with a convenient graphical user interface (https://github.com/eawag-rdm/sav2csv\#sav2csv). Eventually, a subset of Eawag's data will be made available through a publicly available server and tools will be provided to publish submitted datasets semi-automatically to external repositories such as Zenodo. 
Data packages that are uploaded to Eawag's CRD repository are annotated with metadata. The design of the metadata-scheme is one of the project's central challenges. Consideration of metadata structure, extent, and implementation is essential to assure the findability, accessibility and interoperability of data in the repository with the growing number of distributed digital collections [Park and Tosaka, 2010].

Metadata can be as simple as general-purpose vocabularies such as the DCMI Metadata Terms [DCMI, 2012] or the Data Catalog Vocabulary (DCAT) [W3C, 2014], which merely target semantic interoperability. In contrast, the highest level of metadata structure incorporates formally-specified ontologies that encapsulate domain-specific knowledge in a hierarchy of and relations among the terms of a vocabulary. Data annotated in this way can be used to derive new knowledge through automated reasoning as illustrated for water quality monitoring [Jajaga et al., 2015].

The degree of complexity and completeness of metadata provisioning of Eawag's CRD repository is influenced by the effort needed to annotate the data, especially given the lack of available, appropriate domain-specific ontology. This effort must be balanced against the mediumtime gains that can be realized through improved interoperability with other services and the necessity to establish a sustainable solution for the life-time of the repository.

In practice, general bibliographic metadata are represented according to the DataCite Metadata Schema [DataCite Metadata Working Group, 2016] which can be largely mapped to DCAT and DCMI Metadata Terms. This facilitates metadata exchange with DataCite and the DOI registration agency and can be handled by common metadata transmission standards such as OAI-PMH [Open Archives Initiative, 2015]. In addition, a limited number of domain-specific metadata fields are used, which are drawn from existing vocabularies if possible (e.g. for lists of biological taxa). In the absence of existing vocabularies, specific controlled vocabularies are developed in collaboration with Eawag researchers.

Eawag has invested in support staff to meet these technical challenges as well as to provide information on archival standards, file formats, dataset submission guidelines and vocabularies for dataset classification, to co-produce software requirements and to consult on local data management practices.

\section{Management of scientific and technical knowledge}

The scientific literature provides an effective means of compiling formal scientific and technical knowledge from the natural, social and engineering sciences on all topics, including SWM. The scientific literature is well indexed and Eawag researchers have broad access to search tools (e.g., Web of Science, Scopus, etc.) as well as to journals and books through a library that is operated by Eawag on behalf of the four Research Institutes of the ETH Domain (http://www.lib4ri.ch/); the LIB4RI also offers trainings (particularly for doctoral students) on searching the scientific literature. 
Additional access to print materials (especially books) is provided through the Network of Libraries and Information Centers in Switzerland (http://www.nebis.ch/eng/). Eawag researchers also have access to bibliographic tools (e.g., EndNote). In this regard, KM for SWM poses essentially the same challenges as arise in other technical fields.

Scientific and technical conferences (usually organized through professional societies) also provide a venue for exchange of technical knowledge, usually in advance of journal publication. The tendency of individual researchers to align their networks within specific professional societies can lead to a lack of exchange across such societies. The accessibility of conference proceedings to society non-members (or even society members who did not attend a specific conference) can be highly variable. Technical knowledge presented at conferences can, however, be expected to be published (eventually) in the scientific literature.

Various organizations, both governmental and non-governmental, also issue reports containing SWM-related technical knowledge. Examples include water-related publications released by the OECD (Organization for Economic Cooperation and Development, http://www.oecd.org/env/resources/water-publications.htm), the World Bank (http://www.worldbank.org/en/topic/water/research) or UN Water (http://www.unwater.org/publications). Eawag produces only a limited number of self-published reports but does contribute to reports issued by Swiss Federal Offices, most commonly the FOEN (http://www.bafu.admin.ch/?lang=en). Some large projects, especially those funded by the European Union (EU), post comprehensive reports on project websites; relevant examples include: Sustainable Water management Improves Tomorrow's Cities' Health (http://www.switchurbanwater.eu/), Adaptive Strategies to Mitigate the Impacts of Climate Change on European Freshwater Ecosystems (http://www.refresh.ucl.ac.uk/), Transitions to the Urban Water Services of Tomorrow (http://www.trust-i.net/index.php). The Community Research and Development Information Service (CORDIS) provides a searchable index of EU projects (http://cordis.europa.eu/projects/home en.html). While various reports can be found through search engines or through the websites of organizations and are almost always freely available, they are not reliably indexed and the process of finding them is often haphazard. Some organizations (including Eawag) issue newsletters and/or use social media outlets to provide entry points to technical information.

Eawag archives reports to which its staff has contributed (as well as all publications in the scientific literature by Eawag authors) in a structured, searchable institutional repository (https://www.dora.lib4ri.ch/eawag/). Full access to content is available within Eawag; external users can view metadata for all publications and can access content that is not restricted by agreements with external parties (e.g., publishers). 


\section{Management of experiential and practical knowledge}

In contrast to technical knowledge, few (if any) standardized communication channels exist for experiential and practical knowledge. Such knowledge can include both practical intuition regarding complex technical systems that is derived from the experience of operating them and vernacular knowledge held by stakeholders involved in water resources management [Simpson et al., 2015]. A further aspect of experiential knowledge, involving methods and practices of stakeholder engagement, transdisciplinary- and/or action research, is partly systematized through the scientific literature [Jahn et al., 2012; Klein, 2008; Pohl, 2008; Polk, 2015], though this is often fragmented in terms of specific applications (e.g., translational and public health medicine, development for LMICs, etc.).

One of the principal challenges of compiling experiential and practical knowledge is that it is often highly contextual and/or specific to a particular (technical) system. Such knowledge can be partly captured in case studies, which are often included in reports, technical guidance documents or other "gray literature". A significant limitation to the further application and implementation of such knowledge, however, is the lack of a consistent and well-documented review process (quality control). In such cases, the reputation of the organization issuing the document is likely to influence the perception of its reliability. As with technical reports (described above), the lack of reliable indexing tends to result in haphazard access to this knowledge. Nonetheless, generalized searches can provide access to such material and visibility for content providers (including Eawag).

An important factor in documenting experiential knowledge is the involvement of social scientists in water management projects. Although the relevance of social sciences to water management has long been recognized [James, 1974], the recent trend of increasing cooperation among social scientists, natural scientists and engineers (which Eawag supports) has led to improved characterization of social networks and interactions, better incorporation of vernacular knowledge and more reflection on processes of integration and stakeholder engagement [Butterworth et al., 2011; Hoffmann et al., 2017a; Hoffmann et al., 2017b; Simpson et al., 2015]. Without integration of the social sciences, the experience of participants in water management projects (including social learning) is likely to be held only by individuals or within networks and documented only in unsystematic records such as agendas and minutes of public meetings (though these can potentially be analyzed post hoc). Eawag is supporting a Community of Practice (CoP) for individuals employed by or affiliated with Eawag who are working at the interface of science and practice. Such a CoP, composed of individuals who share expertise and experience in a specific domain of activity [Wenger and Snyder, 2000], can facilitate the exchange of experiential knowledge within the network. It remains a challenge to make this knowledge more generally accessible. 


\section{Unresolved issues and challenges in SWM-related KM}

Although Eawag's experience is certainly not unique, it provides insight into the unresolved issues and challenges related to KM, generally, and to KM for SWM in particular.

\section{Information overload and fatigue}

The availability (or over-availability) of information is generally perceived in the context of prior experience and/or technological innovation, making information overload a nearly timeless phenomenon. In the current context of scientific and technical KM, the overall number of records in the Core Collection of the Web of Science is estimated to be growing by about two-to-three percent per year [Larsen and von Ins, 2010] with estimated growth exceeding ten percent per year in the field of water management [Ren et al., 2013].

Associated with information overload [Eppler and Mengis, 2004] and the accompanying information fatigue are a number of coping strategies [Landhuis, 2016]. For scientific and technical knowledge, these may include: over-reliance on metrics (e.g., journal impact factors or citation rates) as proxies for quality, idiosyncratic search strategies with semi-arbitrary criteria for search termination, under-use of less easily accessible information sources such as (printed) books and reliance on recommendations from personal contacts or recommender systems [Beel et al., 2016].

\section{Open access}

The debate over open access is proceeding in a rapidly-evolving context. Publishers are coming under increasing pressure to develop business models for open access that are economically viable for authors and libraries [LERU, 2015]. In late 2016, a German library consortium failed to come to an agreement with the publisher Elsevier; open access and cost were the major points of contention [Vogel, 2016]. In the absence of (or in parallel to) library subscriptions, researchers are likely to rely more heavily on sites such as Google (Scholar) (https://scholar.google.com), Research Gate (https://www.researchgate.net/), Academia (https://www.academia.edu/) or Sci-Hub (https://scihub.io/), without regard to the questionable legal status of documents deposited on (or accessible through) such sites. Preprint servers, mainly arXiv (https://arxiv.org/) and bioR $\chi$ iv (http://biorxiv.org/), are being increasingly used by Eawag researchers, not only to provide open access but also to establish (early) claims to intellectual property. Issues relating to copyright, however, remain murky and publishers have differing policies regarding whether preprints are considered as prior publication [Lawal, 2002].

Eawag does not have formal requirements for open access publication but provides financial support for "gold road" open access publication (though not for "hybrid" open access). "Hybrid" open access, particularly its vulnerability to "double-dipping" by publishers, has been a key issue in arguments with publishers. Eawag also strongly encourages "green road" open access publication of 
post-prints (http://www.lib4ri.ch/services/open-access.html), which makes content available to readers without institutional access to subscribed content. "Green road" open access, however, depends on authors to deliver post-prints to the repository and is, in some cases, blocked by publishers for an embargo period (which is often one to two years). These may be factors in the continuing attractiveness of "hybrid" open access to researchers in environmental science and engineering since many leading journals in this field are not "gold road" open access.

\section{Quality control and collaborative editing}

The proliferation of open access journals has highlighted the issue of quality control in the conventional peer review process, which was exposed in an investigation by the journal Science [Bohannon, 2013]. These concerns are not limited to open access journals, as illustrated by increases in retractions [Steen et al., 2013]. Forums for post-publication review are provided by Faculty of 1000 (F1000, http://f1000.com/), which focuses on biology and medicine, and PubPeer (https://pubpeer.com/). F1000 has expanded its service to include an open publishing platform that offers immediate publication and transparent peer review. This model has been adopted by major funders including the Wellcome Trust (https://wellcomeopenresearch.org/) and the Bill and Melinda Gates Foundation (https://gatesopenresearch.org/). An open review process is conducted by Copernicus Publication, which provides platforms that host unsolicited public comments in parallel to reviews solicited by an editor (http://publications.copernicus.org/services/public peer review.html). The trend toward open and continuous peer review, in which scientific reports are considered as "living documents" [Shanahan, 2015], has the advantage of corresponding to the actual development of scientific understanding. At the same time, it poses challenges to attribution and quality control as implemented in conventional scientific publishing and peer review.

Eawag's current practices rely heavily on (external) peer review, particularly since there is no institutional requirement for internal review of papers that are submitted to peer-reviewed journals. Publication in leading peer-reviewed journals is also an important criterion for decisions on staff advancement (e.g., tenure and promotion).

More generally, there is an implicit assumption of the quality of peer-review in the growing trend toward (comprehensive) systematic reviews, which have been promoted as an antidote to individual bias [Bilotta et al., 2014; Cvitanovic et al., 2015; Spruijt et al., 2014]. This trend runs counter to the past expectation that critical reviews would provide filtering of the available material based on the expert judgment of the author(s) [Nilsen, 2015].

The issue of quality control in the peer-reviewed technical literature is even more acute for reports released by project consortia and/or institutions that are subject to varying (and often unstated) levels of review. The pressure for inclusiveness (which is often an explicit requirement of large programs funded by the EU) is not always compatible with discerning quality control. This 
places an even greater burden on the researcher (or other readers) who might rely on information in the gray literature.

\section{Resource demands}

Quality control clearly demands resources (i.e., the time and attention) of researchers. Indeed, many failings of the peer review system are attributed to the increasing and competing demands on researchers' time. Appropriate curation and archiving of knowledge (including but not limited to data) are also activities that demand both time and expertise. Even updating of websites that function as knowledge portals takes time - often there is no obvious indication when specific websites are no longer actively maintained.

Needed resources can be provided by institutions or funding agencies [Hering, 2015]. When they are not, dangers arise that knowledge platforms will take on an unacknowledged promotional character (serving the self-interest of contributors) and/or that paywalls will be constructed that limit access to knowledge [Hering and Vairavamoorthy, 2017].

\section{Future directions for SWM-related KM}

Eawag attempts, through various measures, to support its researchers in effectively accessing and contributing to the knowledge base for SWM. Some of the challenges and obstacles to this, however, call not only for new tools but also for changes in attitudes and expectations within the SWM research community. As a leading research institute in this field, Eawag can hope to have some influence on these norms and attitudes.

The deluge of scientific and technical literature (including that related to SWM) has been linked with trends in metrics and incentives in academics and funding agencies [Benedictus et al., 2016; Hammarfelt et al., 2016]. In addition, bibliometric indicators have been criticized as having an inhibitory effect on inter- and transdisciplinary research [Zilahy et al., 2009], which is clearly an issue for SWM. Eawag attempts to provide recognition for publications that are directed toward nonacademic audiences (e.g., appearing in trade journals) and, for academic publications, to emphasize quality over quantity. It is, however, open to debate whether quantity (as opposed or in addition to quality) affects impact; an effect of quantity was reported in a recent study in which impact was assessed on the basis of citations in the Web of Science within 3-6 years of publication [Sandstrom and van den Besselaar, 2016]. Nonetheless, Eawag supports the view that a shift to focusing on content, with the understanding that metrics are (at best) surrogates, and attention to impact outside academia are needed [Benedictus et al., 2016].

A change in attitudes at various levels is also needed to combat "platform proliferation syndrome", which reflects the "allure of setting up new initiatives, rather than building on what's already there" [Barnard, 2013]. A key issue is the need to adopt common standards and open data 
principles, which would also eventually support data mining and machine learning (i.e., the semantic web). This approach is being fostered in the development (https://www.okhub.org/) and climate adaptation (https://www.weadapt.org/) communities. The issues of attribution and quality control also need to be addressed in this context. Eawag would be interested in working with other organizations to develop such models for SWM-related knowledge and welcomes input to the Open Science Framework project "Freshwater Knowledge Hub" (https://osf.io/28rhn/).

The lack of accessibility of publications and technical content (e.g., located behind paywalls of publishers or professional societies) is a major impediment to text mining [Peters et al., 2014; Shemilt et al., 2014]. Text and data-mining (TDM) for non-commercial research purposes is explicitly allowed under UK copyright law if the researcher has lawful access (i.e., through a subscription or license) to the material (https://www.jisc.ac.uk/guides/text-and-data-mining-copyright-exception). Collections of open access papers (e.g., https://www.scienceopen.com/) offer a substantial advantage for TDM but this is, of course, limited to the papers in the collection. Other repositories (e.g., PubMed Central) allow papers to be downloaded and read individually, but connection to natural language processing tools needed for effective TDM is limited to the open access subset of the collection [Doring et al., 2016].

The useful application of machine learning to the pharmaceutical patent literature (which has the advantage of being publically accessible) has been demonstrated [Schneider et al., 2016]. This approach could be extremely useful in SWM, but the SWM community would need to coordinate efforts to make this possible.

\section{Concluding comments}

With the SDGs (particularly Goal 6), the SWM community faces both enormous challenges and exciting opportunities. Simply collecting and compiling the monitoring data on indicators to support SDG 6 is a significant task being coordinated through several agencies of the United Nations [UN Water, 2016]. Actually achieving the targets under SDG 6, particularly by 2030 , will require that existing knowledge is marshaled and used to implement solutions [Hering et al., 2016; SDSN, 2015]. Improving knowledge management is an essential component of this task.

The knowledge management issues faced by the SWM community reflect more general issues relating to the overwhelming abundance of scientific and technical knowledge. The SWM community would do well to endorse and support the 12 Vienna Principles - accessibility, discoverability, reusability, reproducibility, transparency, understandability, collaboration, quality assurance, evaluation, validated progress, innovation and public good (http://viennaprinciples.org/) - or the "fair principles" that also address machine learning (https://www.force11.org/fairprinciples). 
In this context, Eawag serves as a microcosm illustrating current practices, challenges and outlooks for SWM-related KM. Eawag's perspective is that of a research institute (i.e., mainly a knowledge provider). Knowledge production, however, also entails the discovery and integration of existing knowledge. Furthermore, it is in the interest of all knowledge providers that the knowledge produced is accessible for implementation as and the basis for further research. No single institution can overcome the barriers to the effective sharing and utilization of knowledge, but together, institutions engaged in SWM can hope to move the SWM-community in this direction. 


\begin{tabular}{|c|c|}
\hline Total staff (number) $^{1}$ & 472 \\
\hline Scientific staff ${ }^{2}$ (number) & 306 \\
\hline with adjunct professorships & 12 \\
\hline with tenured or tenure-track appointments & 76 \\
\hline Joint professors ${ }^{3}$ (number) & 17 \\
\hline Supervised doctoral dissertations ${ }^{4}$ (number) & 144 \\
\hline Supervised Bachelor's and Master's theses (number) & 136 \\
\hline Base funding (CHF) & $61,499,000$ \\
\hline External funding (CHF) & $17,627,000$ \\
\hline Peer-reviewed (ISI) publications (number) & 408 \\
\hline Other (non-ISI) publications ${ }^{5}$ (number) & 146 \\
\hline \multicolumn{2}{|c|}{$\begin{array}{l}1 \text { This number of staff corresponds to } 422 \text { FTE due to part-time appointments. } \\
2 \text { The scientific staff includes those doctoral students who are employed by Eawag. } \\
3 \text { With the exception of Eawag's Director, all joint professors are formally employed by the partner } \\
\text { university. } \\
{ }^{4} \text { This number includes dissertations by doctoral students who are Eawag employees as well as those who } \\
\text { are directly supervised by an Eawag researcher and guest students spending }>50 \% \text { of their working time at } \\
\text { Eawag. } \\
5 \text { This number corresponds to } 74 \text { non-ISI publications (which includes non-reviewed publications in trade } \\
\text { journals) as well as } 72 \text { publications in the category of reports, books, book chapters and proceedings. } \\
\text { Source: Eawag Annual Report (http://www.eawag.ch/en/aboutus/portrait/annual-report/) }\end{array}$} \\
\hline
\end{tabular}


Figures

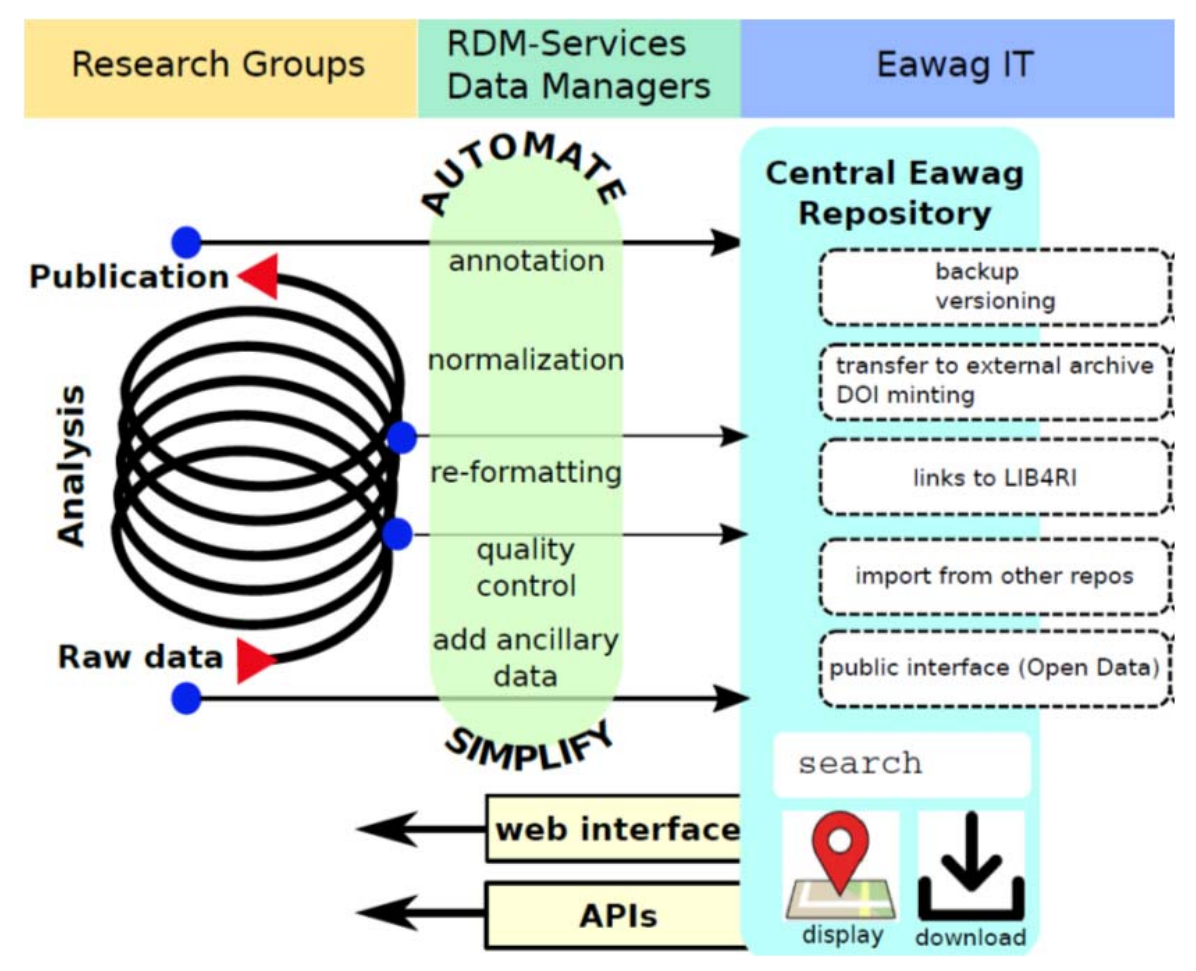

Figure 1. Schematic illustration of Eawag's research data management system. (C) Eawag. Used by permission. 


\section{References}

Amorim, R. C., C. J. A., J. R. da Silva, and C. Ribeiro (2015), A Comparative Study of Platforms for Research Data Management: Interoperability, Metadata Capabilities and Integration Potential, in New Contributions in Information Systems and Technologies. Advances in Intelligent Systems and Computing, edited by A. Rocha, A. Correia, S. Costanzo and L. Reis, pp. 101-111, Springer, Cham.

Barnard, G. (2013), "FEATURE: Portal proliferation syndrome responding to treatment", Climate and Development Knowledge Network, http://cdkn.org/2013/08/feature-portal-proliferationsyndrome-responding-to-treatment/?loclang=en gb (January 6, 2017).

Beel, J., B. Gipp, S. Langer, and C. Breitinger (2016), Research-paper recommender systems: a literature survey, International Journal on Digital Libraries, 17(4), 305-338.

Benedictus, R., F. Miedema, and M. W. J. Ferguson (2016), Fewer numbers, better science, Nature, $538,453-455$.

Bilotta, G. S., A. M. Milner, and I. Boyd (2014), On the use of systematic reviews to inform environmental policies, Environmental Science \& Policy, 42, 67-77.

Bohannon, J. (2013), Who's Afraid of Peer Review?, Science, 342(6154), 60-65.

Briscoe, J. (2011), Making Reform Happen in Water Policy: Reflections from a Practitioner, paper presented at OECD Global Forum on Environment: Making Water Reform Happen, Paris, 2526 October, http://www.oecd.org/env/resources/48925318.pdf.

Butterworth, J., P. McIntyre, and C. da Silva Wells (Eds.) (2011), SWITCH in the city: putting urban water management to the test, IRC International Water and Sanitation Centre, The Hague, The Netherlands.

Cash, D. W., W. C. Clark, F. Alcock, N. M. Dickson, N. Eckley, D. H. Guston, J. Jager, and R. B. Mitchell (2003), Knowledge systems for sustainable development, Proceedings of the National Academy of Sciences of the United States of America, 100(14), 8086-8091.

Cornell, S., F. Berkhout, W. Tuinstra, J. David Tabara, J. Jaeger, I. Chabay, B. de Wit, R. Langlais, D. Mills, P. Moll, I. M. Otto, A. Petersen, C. Pohl, and L. van Kerkhoff (2013), Opening up knowledge systems for better responses to global environmental change, Environmental Science \& Policy, 28, 60-70.

Cvitanovic, C., A. J. Hobday, L. van Kerkhoff, S. K. Wilson, K. Dobbs, and N. A. Marshall (2015), Improving knowledge exchange among scientists and decisionmakers to facilitate the adaptive governance of marine resources: A review of knowledge and research needs, Ocean \& Coastal Management, 112, 25-35.

DataCite Metadata Working Group (2016), "DataCite Metadata Schema Documentation for the Publication and Citation of Research Data. Version 4.0", DataCite e.V., http://doi.org/10.5438/0012 (May 3, 2017).

DCMI (2012), "DCMI Metadata Terms", http://dublincore.org/documents/dcmi-terms/ (April 7, 2017).

Doring, K., B. A. Gruning, K. K. Telukunta, P. Thomas, and S. Gunther (2016), PubMedPortable: A Framework for Supporting the Development of Text Mining Applications, Plos One, 11(10).

Eawag (2011), Eawag: past, present and future, 95 pp, Eawag, Dübendorf, http://www.eawag.ch/fileadmin/Domain1/About/Portraet/Geschichte/Eawag 19362011.pdf.

Eppler, M. J., and J. Mengis (2004), The Concept of Information Overload: A Review of Literature from Organization Science, Accounting, Marketing, MIS, and Related Disciplines, The Information Society, 20(5), 325-344.

Fecher, B., S. Friesike, and M. Hebing (2015), What Drives Academic Data Sharing?, Plos One, 10(2).

Groth, P., A. Gibson, and J. Velterop (2010), The anatomy of a nanopublication, Information Services \& Use, 30(1-2), 51-56.

Hammarfelt, B., G. Nelhans, P. Eklund, and F. Åström (2016), The heterogeneous landscape of bibliometric indicators: Evaluating models for allocating resources at Swedish universities, Research Evaluation. 
Hering, J. G. (2015), Do we need "more research" or better implementation through knowledge brokering?, Sustain Sci, 1-7.

Hering, J. G. (2017), Water Data Portals: An Annotated List, 4 pp, https://doi.org/10.5281/zenodo.495080.

Hering, J. G., and K. Vairavamoorthy (2017), Harvesting Experience to Support Sustainable Urban Water Management, in Assessing Water Megatrends, edited by A. K. Biswas and C. Tortajada, Springer, Berlin, preprint available at: https://osf.io/zuwnr.

Hering, J. G., S. Maag, and J. L. Schnoor (2016), A Call for Synthesis of Water Research to Achieve the Sustainable Development Goals by 2030, Environmental Science \& Technology, 50(12), 61226123.

Hering, J. G., D. L. Sedlak, C. Tortajada, A. K. Biswas, C. Niwagaba, and T. Breu (2015), Local perspectives on water, Science, 349(6247), 479-480.

Hoffmann, S., C. Pohl, and H. J. G. (2017a), Methods and procedures of transdisciplinary knowledge integration: empirical insights from four thematic synthesis processes, Ecology and Society.

Hoffmann, S., C. Pohl, and J. G. Hering (2017b), Exploring transdisciplinary integration within a large research program: Empirical lessons from four thematic synthesis processes, Research Policy, 46(3), 678-692.

Jahn, T., M. Bergmann, and F. Keil (2012), Transdisciplinarity: Between mainstreaming and marginalization, Ecological Economics, 79, 1-10.

Jajaga, E., L. Ahmedi, and F. Ahmedi (2015), An Expert System for Water Quality Monitoring Based on Ontology, in Metadata and Semantics Research: 9th Research Conference, MTSR 2015, Manchester, UK, September 9-11, 2015, Proceedings, edited by E. Garoufallou, R. J. Hartley and P. Gaitanou, pp. 89-100, Springer International Publishing, Cham.

James, L. D. (Ed.) (1974), Man and Water: The Social Sciences in Management of Water Resources, University Press of Kentucky.

Joseph, H. (2016), The evolving U.S. policy environment for open research data, Information Services \& Use, 36, 45-48.

Klein, J. T. (2008), Evaluation of interdisciplinary and transdisciplinary research - A literature review, American Journal of Preventive Medicine, 35(2), S116-S123.

Kowalczyk, S., and K. Shankar (2011), Data Sharing in the Sciences, Annual Review of Information Science and Technology, 45, 247-294.

Landhuis, E. (2016), Information overload How to manage the research-paper deluge? Blogs, colleagues and social media can all help, Nature, 535(7612), 457-458.

Larsen, P. O., and M. von Ins (2010), The rate of growth in scientific publication and the decline in coverage provided by Science Citation Index, Scientometrics, 84(3), 575-603.

Lawal, I. (2002), Scholarly Communication: The Use and Non-Use of E-Print Archives for the Dissemination of Scientific Information, VCU Libraries Faculty and Staff Publications, Paper 4.

LERU (2015), "Christmas is over. Research funding should go to research, not to publishers!", League of European Research Universities, http://www.leru.org/index.php/public/news/christmasis-over-research-funding-should-go-to-research-not-to-publishers/ (Novermber 26, 2015, 2015).

Martinuzzi, A., and M. Sedlacko (Eds.) (2016), Knowledge Brokerage for Sustainable Development, 330 pp., Greenleaf Publishing, Saltaire.

Mays, L. W. (Ed.) (2010), Ancient Water Technologies, 280 pp., Springer, Dordrecht.

Michener, W. K. (2015), Ecological data sharing, Ecological Informatics, 29, 33-44.

Nilsen, P. (2015), Making sense of implementation theories, models and frameworks, Implementation Science, 10(53).

Open Archives Initiative (2015), "The Open Archives Initiative Protocol for Metadata Harvesting", https://www.openarchives.org/OAl/openarchivesprotocol.html (April 7, 2017).

Pampel, H., P. Vierkant, F. Scholze, R. Bertelmann, M. Kindling, J. Klump, H.-J. Goebelbecker, J. Gundlach, P. Schirmbacher, and U. Dierolf (2013), Making Research Data Repositories Visible: The re3data.org Registry, Plos One, 8(11). 
Park, J. R., and Y. Tosaka (2010), Metadata Creation Practices in Digital Repositories and Collections: Schemata, Selection Criteria, and Interoperability, Information Technology and Libraries, 29(3), 104-116.

Peters, D. P. C., K. M. Havstad, J. Cushing, C. Tweedie, O. Fuentes, and N. Villanueva-Rosales (2014), Harnessing the power of big data: infusing the scientific method with machine learning to transform ecology, Ecosphere, 5(6).

Piwowar, H. A., and T. J. Vision (2013), Data reuse and the open data citation advantage, Peerj, 1.

Pohl, C. (2008), From science to policy through transdisciplinary research, Environmental Science \& Policy, 11(1), 46-53.

Polk, M. (2015), Transdisciplinary co-production: Designing and testing a transdisciplinary research framework for societal problem solving, Futures, 65, 110-122.

Ren, J.-L., P.-H. Lyu, X.-M. Wu, F.-C. Ma, Z.-Z. Wang, and G. Yang (2013), An Informetric Profile of Water Resources Management Literatures, Water Resources Management, 27(13), 46794696.

Roche, D. G., L. E. B. Kruuk, R. Lanfear, and S. A. Binning (2015), Public Data Archiving in Ecology and Evolution: How Well Are We Doing?, Plos Biology, 13(11), 12.

Sandstrom, U., and P. van den Besselaar (2016), Quantity and/or Quality? The Importance of Publishing Many Papers, Plos One, 11(11).

Schneider, N., D. M. Lowe, R. A. Sayle, M. A. Tarselli, and G. A. Landrum (2016), Big Data from Pharmaceutical Patents: A Computational Analysis of Medicinal Chemists' Bread and Butter, Journal of Medicinal Chemistry, 59(9), 4385-4402.

SDSN (2015), Getting Started with the Sustainable Development Goals, 38 pp, Sustainable Development Solutions Network, http://unsdsn.org/wp-content/uploads/2015/12/151211getting-started-guide-FINAL-PDF-.pdf.

Sedlak, D. (2014), Water 4.0: The Past, Present, and Future of the World's Most Vital Resource, 332 pp., Yale University Press New Haven.

Shanahan, D. R. (2015), A living document: reincarnating the research article, Trials, 16, 151.

Shemilt, I., A. Simon, G. J. Hollands, T. M. Marteau, D. Ogilvie, A. O'Mara-Eves, M. P. Kelly, and J. Thomas (2014), Pinpointing needles in giant haystacks: use of text mining to reduce impractical screening workload in extremely large scoping reviews, Research Synthesis Methods, 5(1), 31-49.

Simpson, H., R. de Loe, and J. Andrey (2015), Vernacular Knowledge and Water Management Towards the Integration of Expert Science and Local Knowledge in Ontario, Canada, Water Alternatives-an Interdisciplinary Journal on Water Politics and Development, 8(3), 352-372.

Soranno, P. A., K. S. Cheruvelil, K. C. Elliott, and G. M. Montgomery (2015), It's Good to Share: Why Environmental Scientists' Ethics Are Out of Date, Bioscience, 65(1), 69-73.

Spruijt, P., A. B. Knol, E. Vasileiadou, J. Devilee, E. Lebret, and A. C. Petersen (2014), Roles of scientists as policy advisers on complex issues: A literature review, Environmental Science \& Policy, 40, 16-25.

Steen, R. G., A. Casadevall, and F. C. Fang (2013), Why Has the Number of Scientific Retractions Increased?, Plos One, 8(7).

Tsoukas, H. (2011), How Should We Understand Tacit Knowledge? A Phenomenological View, in Handbook of Organizational Learning and Knowledge Management, Second Edition, edited by M. Easterby-Smith and M. A. Lyles, pp. 454-476, John Wiley \& Son, New York.

UN (2015), Transforming our World: The 2030 Agenda for Sustainable Development, 41 pp, https://sustainabledevelopment.un.org/content/documents/21252030\%20Agenda\%20for\%2 OSustainable\%20Development\%20web.pdf.

UN Water (2016), Integrated Monitoring Guide for SDG 6: Targets and global indicators, 25 pp, UN Water, http://www.unwater.org/fileadmin/user upload/unwater new/docs/SDG\%206\%20targets\% 20and\%20global\%20indicators 2016-07-19.pdf. 
van Kerkhoff, L. (2013), Knowledge Governance for Sustainable Development: A Review, Challenges in Sustainability, 1(2), 82-93.

van Kerkhoff, L., and L. Lebel (2006), Linking knowledge and action for sustainable development, in Annual Review of Environment and Resources, edited, pp. 445-477.

van Kerkhoff, L., and N. A. Szlezak (2016), The role of innovative global institutions in linking knowledge and action, Proceedings of the National Academy of Sciences of the United States of America, 113(17), 4603-4608.

Vines, T. H., R. L. Andrew, D. G. Bock, M. T. Franklin, K. J. Gilbert, N. C. Kane, J. S. Moore, B. T. Moyers, S. Renaut, D. J. Rennison, T. Veen, and S. Yeaman (2013), Mandated data archiving greatly improves access to research data, Faseb Journal, 27(4), 1304-1308.

Vogel, G. (2016), Thousands of German researchers set to lose access to Elsevier journals, Science, doi: $10.1126 /$ science.aal0552.

W3C (2014), "Data Catalog Vocabulary (DCAT)", World Wide Web Consortium, https://www.w3.org/TR/vocab-dcat/ (April 7, 2017).

Wenger, E. C., and W. M. Snyder (2000), Communities of practice: The organizational frontier, Harvard Business Review, 78(1), 139-+.

Zilahy, G., D. Huisingh, M. Melanen, V. D. Phillips, and J. Sheffy (2009), Roles of academia in regional sustainability initiatives: outreach for a more sustainable future, Journal of Cleaner Production, 17, 1053-1056. 